\title{
An analysis of brachytherapy with computed tomography-guided permanent implantation of lodine- 125 seeds for recurrent nonkeratin nasopharyngeal carcinoma
}

\author{
This article was published in the following Dove Press journal: \\ OncoTargets and Therapy \\ 2 May 2015 \\ Number of times this article has been viewed
}

\section{Xinying Shen ${ }^{1,2}$ \\ Yong $\mathrm{Li}^{2}$ \\ Yanfang Zhang ${ }^{2}$ \\ Jian Kong ${ }^{2}$ \\ Yanhao $\mathrm{Li}^{1}$}

'Department of Interventional Radiology, Nanfang Hospital, Southern Medical University, Guangzhou, ${ }^{2}$ Department of Interventional Radiology, Shenzhen People's Hospital, The Second Clinical Medical College of Jinan University, Shenzhen, People's Republic of China
Correspondence: Yanhao Li

Department of Interventional Radiology, Nanfang Hospital, Southern Medical University, 1838 Guangzhou Avenue North, Guangzhou, Guangdong 5I05I5, People's Republic of China Tel +862061642082

Emailyanhaoli@yahoo.com
Background: ${ }^{125}$ I seed implantation is a new method in treatment of nasopharyngeal carcinoma (NPC), and it is worthwhile to evaluate its feasibility. In this study, we performed brachytherapy with computed tomography (CT)-guided permanent implantation of ${ }^{125} \mathrm{I}$ seeds in the treatment of patients with the recurrence of NPC.

Methods: A total 30 patients (20 male and ten female) at the median age of 55 (range 25-80) years were diagnosed with recurrent nonkeratin NPC, with a total 38 lesions and a short diseasefree interval (median $\sim 11$ months) after primary radiotherapy alone or combined with chemotherapy. Patients received CT scan, starting from 2 months after the treatment. Follow-up was conducted for $\sim 2-38$ months to observe the local control rate and overall survival rate. We also analyzed the possible correlation between survival periods and the status of recurrent tumors.

Results: The local control rates at $6,12,24,30$, and 36 months after the procedure of ${ }^{125} \mathrm{I}$ seed implantation were $86.8 \%, 73.7 \%, 26.3 \%, 15.8 \%$, and $5.3 \%$, respectively. The overall 1-, $2-$, and 3 -year survival rates were $80.0 \%(24 / 30), 30.0 \%(9 / 30)$, and $6.7 \%(2 / 30)$, respectively, with a median survival period of 18 months (17.6 \pm 8.6 months). Interestingly, the survival periods of the patients who had primary radiotherapy with or without chemotherapy were $15.8 \pm 7.9$ and $24.3 \pm 7.9$ months, respectively. Kaplan-Meier survival analysis demonstrated that $\chi^{2}$ (log rank) was 7.555 , with very significant difference $(P<0.01)$. The survival periods of patients in tumor stages I, II, III, and IV were $25.4 \pm 8.7,19.8 \pm 9.4,16.1 \pm 4.5$, and $12.8 \pm 7.8$ months, respectively, with significant differences $(P<0.05)$.

Conclusion: Our data suggest that the survival period of recurrent NPC patients after ${ }^{125}$ I seed implantation is inversely related to the tumor stages of the recurrence but not to chemotherapy after the primary radiotherapy. Therefore, CT-guided ${ }^{125} \mathrm{I}$ seed implantation can be set for treatment of recurrent NPC, for better survival rate with minimal damage.

Keywords: CT-guided ${ }^{125}$ I seed, radiochemotherapy, NPC

\section{Introduction}

Nasopharyngeal carcinoma (NPC) caused 65,000 deaths worldwide in 2010. ${ }^{1}$ Although it is a relatively uncommon disease in Western countries $(0.5-2 / 100,000 /$ year $)$, nasopharyngeal carcinoma is a common type of head and neck cancers in southern China (30-80/100,000/year). ${ }^{2}$ The World Health Organization (WHO) has classified NPC into three histologic types: type I (keratinizing), type II (differentiated nonkeratinizing), and type III (undifferentiated nonkeratinizing). In southern China, $2 \%$ of NPC is type I, 3\% type II, and 95\% type III. ${ }^{3}$ Because of their anatomic situation at the base of skull, most nasopharyngeal carcinomas spread early to cervical nodes and are difficult 
to treat with surgical operation. The primary treatment of NPC is radiotherapy, usually combined with chemotherapy. ${ }^{4}$ The improvement of therapeutic strategies increased the 5-year survival rate of NPC from $\sim 50 \%$ in the 1980 s to $\sim 70 \%$ in the 1990 s and is currently $\sim 80 \%{ }^{5,6}$ However, the recurrence rate of NPC following the initial radiotherapy is $15 \%-58 \% .^{7-10}$ The recurrence of tumors reduces their sensitivity to radiotherapy and leads to a poor prognosis. Therefore, recurrence becomes a major modality of failure in NPC patients and a challenge to clinicians.

Current retreatment methods of the locally recurrent NPC include external radiotherapy, stereotactic radiosurgery, and brachytherapy, alone or in combination. ${ }^{4}$ Permanent implantation of ${ }^{125}$ I seeds has a major advantage of delivering a high dose of irradiation to cancers of the nasopharynx with a very sharp fall off outside the implanted volume. ${ }^{1-13}$ Computed tomography (CT)-guided permanent brachytherapy was initially used for treating liver malignancies ${ }^{14,15}$ and now is also widely applied in treatment of NPC. ${ }^{16}$ The ${ }^{125} \mathrm{I}$ seeds have an average energy of $27.4-31.4 \mathrm{keV}$. After implantation of ${ }^{125} \mathrm{I}$ seeds, the gamma rays are concentrated in the immediate surroundings of the target tissues (valid radius $\sim 1.7 \mathrm{~cm}) .{ }^{17}$ This novel technique delivers high-dose radiation that ensures protracted cancer cell killing over a period of several months.

Many lines of evidence have shown that the implantation of ${ }^{125}$ I radioactive seeds into tissues of NPC significantly increases therapeutic doses of radiation in the target area of tumors and as well, probably reduces the unnecessary damage in surrounding heathy tissues. In this study, we have analyzed and evaluated the efficacy of CT-guided ${ }^{125}$ I seed implantation in the treatment of recurrent nonkeratin nasopharyngeal carcinoma at Shenzhen People's Hospital. Our results suggest that this therapeutic method can be used for treating the recurrence of NPC after radiotherapy with or without chemotherapy.

\section{Patients and methods}

\section{Patient selection}

Between 2008 and 2014, 30 patients were diagnosed with the recurrence of nonkeratin NPC (Table 1) and selected for the treatment of brachytherapy with permanent implantation of ${ }^{125}$ I seeds. The diagnoses were made by needle biopsy. The lesions were located in the pharyngeal recess, parapharyngeal space, nasopharynx side, retropharyngeal lymph nodes, and neck, distinct from the skull base and not associated with any distant metastasis. The enrolled patients were informed of the potential risks of the proposed CT-guided ${ }^{125} \mathrm{I}$ seed
Table I Patient characteristics $(n=30)$

\begin{tabular}{ll}
\hline Characteristics & Number (\%) \\
\hline Sex & \\
Male & $20(66.7)$ \\
Female & $10(33.3)$ \\
Age & $51.2 \pm 13.9$ (years) \\
Range & $25-80$ \\
Recurrence & $30(100)$ \\
DFI & $11.0 \pm 3.4$ (months) \\
Histology & \\
WHO I & $0(0)$ \\
WHO II & $23(77.7)$ \\
WHO III & $7(23.3)$ \\
Tumor stage & \\
I & $5(16.7)$ \\
II & $8(26.7)$ \\
III & $8(26.7)$ \\
IV & $9(30.0)$ \\
Previous radiotherapy & $30(100)$ \\
Previous chemotherapy & $20(66.7)$ \\
\hline
\end{tabular}

Notes: WHO type I, keratinizing; type II, differentiated nonkeratinizing; type III, undifferentiated nonkeratinizing. Tumor stage according to TNM staging: stage I, TI (confined to nasopharynx, or extension to oropharynx/nasal cavity without posterolateral spread), NO (no regional metastasis), M0 (no metastasis); stage II, T2 (extension into posterolateral pharyngeal soft tissues), NO, MO, or T2, NI (unilateral metastasis to cervical nodes, $<6 \mathrm{~cm}$ size, not level IV/Vb, and/or unilateral or bilateral involvement of retropharyngeal nodes, $<6 \mathrm{~cm}$ size), MO; stage III, T3 (invasion of bony structures, skull base, and/or sinuses), N0 to N2 (bilateral metastasis to cervical nodes, $<6 \mathrm{~cm}$ size, not level IV/Vb), M0, or T2, N2, M0; and stage IV, any T (TI, T2, $\mathrm{T} 3$, or T4: intracranial extension, cranial nerve involvement, spread to hypopharynx/ orbit/infratemporal fossa), any N (NI, N2, or N3: involvement of nodes in levels IVI $\mathrm{Vb}$, supraclavicular fossa), $\mathrm{MO} .^{27}$

Abbreviations: DFI, disease-free interval; $\mathrm{M}$, metastasis; $\mathrm{N}$, node; T, tumor; $\mathrm{WHO}$, World Health Organization.

implantation therapy, and provided written informed consent before beginning the treatment. The protocol was approved by the ethics committee of Jinan University.

\section{Patient information}

A total of 30 patients (20 male and ten female) at the age of 51.2 \pm 13.9 years (median 55, range 25-80 years) were treated with ${ }^{125} \mathrm{I}$ seed implantation. All tumors were recurrent nonkeratin NPC. The interval time from the end of the first course of radiotherapy to diagnosis of recurrence (diseasefree interval [DFI]) was $11.0 \pm 3.4$ months (median 11 , range 6-20 months). The tumor diameters were $2.5 \pm 1.2 \mathrm{~cm}$ and varied from 1.0 to $5.9 \mathrm{~cm}$ ( 16 lesions $\leq 2 \mathrm{~cm}, 20$ lesions $2-5 \mathrm{~cm}$, and two lesions $\geq 5 \mathrm{~cm}$ ). Patients had previously been treated with radiotherapy alone or followed with chemotherapy (Table 1). The doses of the first radiotherapy were 70 Gy, 35 times, 7 weeks (64 88 Gy, 32 44 times, 6.5 8.5 weeks). After radiotherapy, 20 patients were further treated with the chemotherapy regimens, which included cisplatin (100-120 $\mathrm{mg} \cdot \mathrm{m}^{-2}$, intravenous drip) and 5-fluorouracil (800-1,000 $\mathrm{mg} \cdot \mathrm{m}^{-2}$, for 5 days, intravenous drip) at 3-week 
intervals. No patients received chemotherapy after ${ }^{125} \mathrm{I}$ seed implantation.

\section{Instruments}

For ${ }^{125} \mathrm{I}$ seed implantation, we used a HiSpeed Advantage Genesis CT scanner (GE Healthcare, Little Chalfont, UK) and a treatment-planning system (Beijing University of Aeronautics and Astronautics, Beijing, People's Republic of China), and the instruments of seed implantation included 18G implantation needles and a turntable implantation gun. The diameter and length of each ${ }^{125}$ I seed (Beijing Atom and High Technique Industries Inc. Pharmaceuticals Co Ltd, Ningbo, People's Republic of China) was $0.8 \mathrm{~mm}$ and $4.5 \mathrm{~mm}$, respectively. The thickness of the wall of the titanium capsule was $0.05 \mathrm{~mm}$. The ${ }^{125} \mathrm{I}$ emits gamma rays $(5 \%$ of $35.5 \mathrm{keV}$ and $95 \%$ of $28 \mathrm{keV}$ ) with a half-life of 59.4 days, half-value thickness of $0.025 \mathrm{~mm}$ of lead, penetration of 17 $\mathrm{mm}$, and incipient rate of $7 \mathrm{cGy} /$ hour. All ${ }^{125}$ I seeds $(6,711 /$ BT- $\left.{ }^{125} \mathrm{I}\right)$ were delivered in a type-A pack that had passed leak detection and activity series tests.

\section{Patient preparation}

At 1-2 weeks prior to the procedure, patients were examined, using CT scans with a thickness of $5 \mathrm{~mm}$, for the detailed tumor volumes. The planning target volume included the entire gross tumor volume and $0.5-1.0 \mathrm{~cm}$ margins, and was prescribed the minimal peripheral dose of ${ }^{125}$ I seeds (median 130 Gy, range 90-160 Gy).

\section{I seed implantation}

Before ${ }^{125}$ I seed implantation, patients fasted for 1 to 3 hours. In a specially designated operating room patients were given sedatives and local anesthesia. The procedure included making a $3 \mathrm{~mm}$ incision on the skin and inserting a seed implantation applicator into each tumor under the guidance of CT with caution in avoiding puncture of large blood vessels or important organs. The ${ }^{125} \mathrm{I}$ seeds $(0.8 \mathrm{mCi})$ were implanted into each tumor, and then, the catheters were retracted and incisions were bound and compressed. Medical personal were protected by wearing lead gloves, hats, and other protective clothing. A special measurement of the ray dosage was performed to detect any missing radioactive seeds after the procedure.

\section{Patient assessment and follow-up}

After the implantation of ${ }^{125}$ I seeds was completed, vital signs were monitored and recorded for 24 hours. Patients were hospitalized for at least 3 days. A clinical examination and CT scan were performed every 2-3 months until death. To evaluate the therapeutic feasibility of ${ }^{125}$ I seed implantation, we used criteria according to the Response Evaluation Criteria in Solid Tumors (RECIST), which include: complete response (CR), defined as the disappearance of all target lesions; partial response (PR), defined as a decrease of at least $30 \%$ in the sum of the largest diameter of target lesions; stable disease (SD), defined as neither sufficient shrinkage to qualify for PR nor sufficient increase to qualify for progressive disease (PD); PD, defined as at least a $20 \%$ increase in the sum of the longest diameter of target lesions; and total treatment response rate (RR), defined as CR cases + PR cases/ case number (Table 2).

\section{Statistical analyses}

All values are presented as mean \pm standard deviation. Student's $t$-test, analysis of variance (ANOVA) test, and Kaplan-Meier survival analysis were used to evaluate the significance of differences. $P<0.05$ was considered significant and $P<0.01$, very significant.

\section{Results}

\section{Treatment and follow-up}

The ${ }^{125} \mathrm{I}$ seed implantation procedure required 60 to 180 minutes and was guided by CT scan imaging according to the treatment-planning system established (Figure 1). The

Table 2 Clinical efficacy of recurrent NPC with ${ }^{125}$ seed implantation therapy

\begin{tabular}{|c|c|c|c|c|c|}
\hline \multirow[t]{2}{*}{ Tumor Dia (cm) } & \multicolumn{4}{|c|}{ Local control efficacy (\%) } & \multirow[t]{2}{*}{$\mathbf{R R}$} \\
\hline & $\overline{C R}$ & PR & SD & PD & \\
\hline$\leq 2$ & $13(81.3)$ & $3(18.8)$ & $0(0.0)$ & $0(0.0)$ & $16 / 16(100.0)$ \\
\hline $2-5$ & $14(70.0)$ & $4(20.0)$ & $2(10.0)$ & $0(0.0)$ & $16 / 20(80.0)$ \\
\hline$>5$ & $0(0.0)$ & I $(50.0)$ & I (50.0) & $0(0.0)$ & $\mathrm{I} / 2(50.0)$ \\
\hline Total & & & & & $35 / 38(92.1)$ \\
\hline
\end{tabular}

Notes: CR, disappearance of all target lesions; PR, a decrease of at least $30 \%$ in the sum of the largest diameter of target lesions; SD, neither sufficient shrinkage to qualify for PR nor sufficient increase to qualify for PD; PD, at least a $20 \%$ increase in the sum of the longest diameter of target lesions; RR, (cases of CR + cases of PR)/number of NPC cases.

Abbreviations: CR, complete response; Dia, diameter; NPC, nasopharyngeal carcinoma; PD, progressive disease; PR, partial response; RR, total treatment response rate; SD, stable disease. 

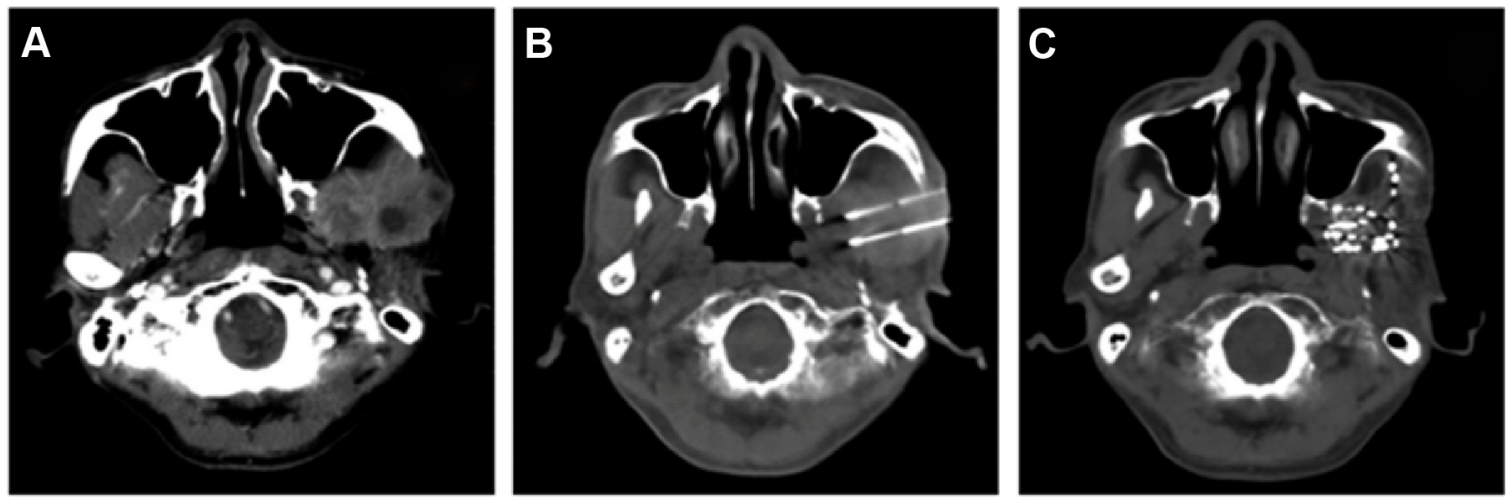

Figure I CT images of a recurrent NPC patient.

Notes: (A) A recurrent enhancing mass with NPC following initial radiochemotherapy. (B) CT-guided ${ }^{125}$ seed implantation. (C) Resolution of the tumor mass at 2 months post- ${ }^{125}$ brachytherapy.

Abbreviations: CT, computed tomography; NPC, nasopharyngeal carcinoma.

${ }^{125} \mathrm{I}$ seeds implanted were distributed with an interval of $1 \mathrm{~cm}$ between any two seeds, and the radioactive activity per seed was $29.6 \mathrm{MBq}$ to obtain a peripheral dose of 90-160 Gy. The median number of seeds implanted per patient was 42 (range 4-112), and patients underwent one to four ${ }^{125} \mathrm{I}$ seed implantation sessions (median of two). All patients were successfully implanted. The range of follow-up period was from 2 to 38 months for monitoring the local control rate, overall survival rate, and any clinical complications.

CT imaging performed prior to ${ }^{125} \mathrm{I}$ seed implantation revealed images of all the tumors. When the same imaging was performed 2 months after ${ }^{125}$ I seed implantation, CT showed resolution of the tumor mass, which exhibited the size and shape of the inactivated tumor (Figure 1 and 2).

\section{Local control}

Local control rates for the recurrent NPC treated with ${ }^{125}$ I seed implantation at 3, 6, 12, 18, 24, 30, and 36 months after the procedure were $92.1 \%(35 / 38), 86.8 \%$ (33/38), $73.7 \%(28 / 38)$, $44.7 \%(17 / 38), 26.3 \%(10 / 38), 15.8 \%(6 / 38)$, and 5.3\% (2/38), respectively. For tumors $\leq 2 \mathrm{~cm}$ in diameter, ${ }^{125} \mathrm{I}$ seed implantation treatment achieved a CR rate of $81.3 \%(13 / 16)$, a PR rate of $18.8 \%(3 / 16)$, and a RR of $100 \%$ (16/16); for tumors of $2-5 \mathrm{~cm}$ in diameter, the CR rate was $70.0 \%(12 / 20)$, PR was $20.0 \%(4 / 20)$, SD rate was $20.0 \%(2 / 20)$, and RR was $80 \%$ (16/20); for tumors $>5 \mathrm{~cm}$ in diameter, the PR was $50.0 \%(1 / 2)$, SD was $50.0 \%(1 / 2)$, and the RR was $50 \%(1 / 2)$. The overall RR was $92.1 \%(35 / 38)$ in all cases (Table 2).

\section{Survival rates}

After the ${ }^{125}$ I seed implantation, the overall 1-, 2-, and 3 -year survival rates were $80.0 \%(24 / 30), 30.0 \%$ (9/30), and $6.7 \%(2 / 30)$, respectively, with a median survival period of 18 months (17.6 \pm 8.6 months). Furthermore, the 1-, 2-, and 3-year survival rates of ${ }^{125} \mathrm{I}$ seed implantation-treated patients with or without previous chemotherapy after radiotherapy
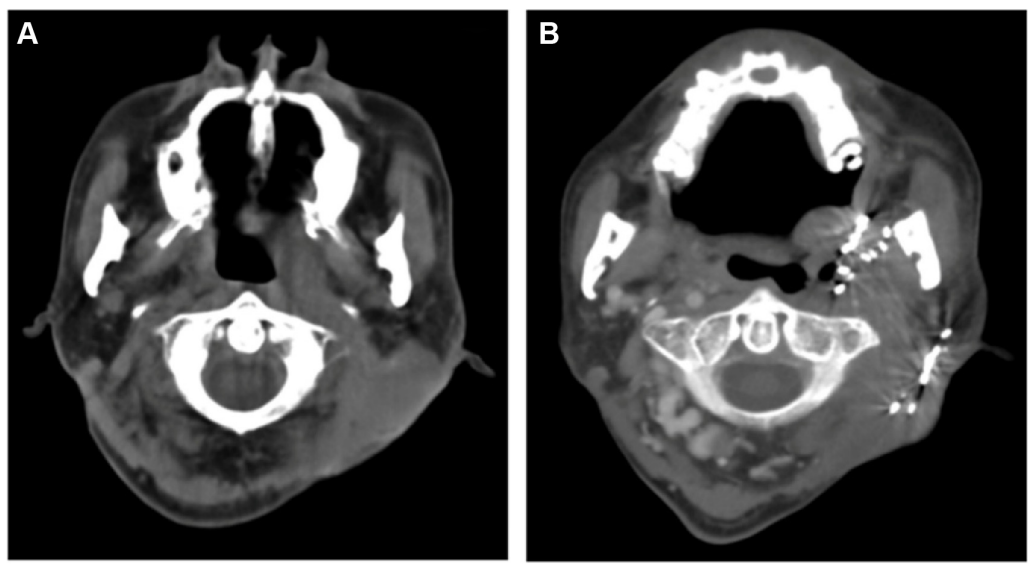

Figure 2 Metastasis of nasopharyngeal carcinoma.

Notes: (A) Lymph node metastasis of NPC behind the ear. (B) CT-image of resolution of tumor mass at 6 months post- ${ }^{125}$ brachytherapy. Abbreviations: CT, computed tomography; NPC, nasopharyngeal carcinoma. 
were $70.0 \%(14 / 20)$ and $100 \%(10 / 10), 20 \%(4 / 20)$ and $50 \%$ $(5 / 10)$, and $5 \%(1 / 20)$ and $10 \%(1 / 10)$, respectively. After ${ }^{125}$ I seed implantation, the survival period of patients with primary radiotherapy alone was $24.3 \pm 7.9$ months, longer than that of patients with primary radio- and chemotherapy, 15.8 \pm 7.9 months. Kaplan-Meier survival analysis demonstrated that $\chi^{2}(\log$ rank) was $7.555(P<0.001)$, with very significant difference (Figure 3).

\section{Survival periods and status of tumors}

The survival period of all 30 patients after ${ }^{125} \mathrm{I}$ seed implantation was 17.6 \pm 8.6 months $(\mathrm{n}=30$ ) (Figure 3 ). The survival periods of patients with the tumor size $\leq 2 \mathrm{~cm}$ and $>2 \mathrm{~cm}$ were $10.1 \pm 2.9$ $(\mathrm{n}=7)$ and $11.3 \pm 3.6$ months $(\mathrm{n}=23)$, respectively, without significant difference $(P>0.05)$ (Figure $4 \mathrm{~A})$. The survival periods of patients with differentiated and undifferentiated nonkeratin NPC were 16.9 $\pm 8.4(\mathrm{n}=23)$ and $24.1 \pm 8.1$ months $(\mathrm{n}=7)$, respectively, without significant difference $(P>0.05)$ (Figure 4B). In contrast, the survival periods of patients with the tumor stages I, II, III, and IV were 25.4 $\pm 8.7(\mathrm{n}=5)$, 19.8 $\pm 9.4(\mathrm{n}=8), 16.1 \pm 4.5(\mathrm{n}=8)$, and $12.8 \pm 7.8(\mathrm{n}=9)$ months, respectively, with significant differences $(P<0.05$, ANOVA tests) (Figure 4D). These data suggest that the survival period of NPC patients after ${ }^{125} \mathrm{I}$ seed implantation is inversely related to the tumor stage. We also analyzed survival periods of 13 patients with stage III recurrent NPC after ${ }^{125}$ I seed implantation therapy. The survival period of five patients with the primary

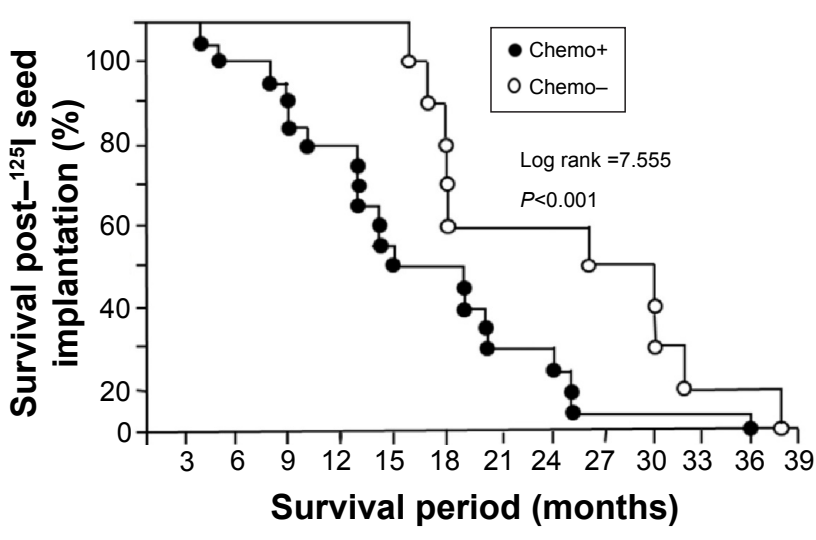

Figure 3 Kaplan-Meier survival curves of patients with the recurrent NPC post- ${ }^{125}$ seed implantation therapy.

Notes: Survival rates post- ${ }^{125}$ | seed implantation therapy, for NPC patients who received primary radiotherapy with or without chemotherapy. The I-, 2-, and 3-year survival rates of ${ }^{125}$ seed implantation-treated patients with or without previous chemotherapy, after radiotherapy were $70.0 \%$ and $100 \%, 20 \%$ and $50 \%$, and $5 \%$ and $10 \%$, respectively. The survival periods of patients with and without chemotherapy were $15.8 \pm 7.9$ and $24.3 \pm 7.9$ months, respectively. Kaplan-Meier survival analysis demonstrated that $\chi^{2}$ (log rank) was 7.555 , with very significant difference $(P<0.001)$. After ${ }^{125}$ s seed implantation therapy, I-, 2-, and 3-year survival rates of all 30 recurrent NPC patients were $80.0 \%, 30.0 \%$, and $6.7 \%$, respectively, with a median survival period of 18 months.

Abbreviations: chemo, chemotherapy; NPC, nasopharyngeal carcinoma. radiotherapy alone was $18.6 \pm 4.7$ months, longer than that of eight patients with the primary combined radiochemotherapy, $12.0 \pm 1.9$ months, with very significant difference $(P<0.01)$ (Figure 4C). The interesting results question the effect of radio- and chemotherapy in primary NPC.

\section{Discussion}

An extremely poor prognosis has been observed in patients with the local recurrence of NPC. For example, one analysis of 219 cases in the 1980s reported a 5-year survival rate was less than $1 \%$ if the patients were without any treatment. ${ }^{18}$ Another analysis of 891 patients with locally recurrent NPC showed a 5-year survival rate of 14\%, although 79\% (706/891) of patients had been reirradiated with various techniques and doses..$^{19}$ Accordingly, the local recurrence of NPC is $8 \%-58 \%$ (median $34 \%$ ). ${ }^{19}$ Therefore, the high frequency of the recurrence is a major cause of the mortality in NPC. To develop efficient methods for treatment of the recurrent disease is still a challenge in NPC treatment. Several techniques have been used to treat the recurrent NPC, including external radiotherapy, stereotactic radiosurgery, nasopharyngectomy, and brachytherapy, alone or combined with further chemotherapy. ${ }^{20-23}$ Among these therapies, brachytherapy with ${ }^{125}$ I seed implantation has been used widely in salvage treatment of the NPC recurrence. ${ }^{4}$

To estimate the efficacy of ${ }^{125}$ I seed implantation therapy in certain NPC types, we selected 30 patients with the recurrence of differentiated or undifferentiated nonkeratinizing cancers (WHO type II or III) (Figures 1 and 2). All patients had a short DFI, representing the interval time from the end of first course of radiotherapy to diagnosis of recurrence (6-12 months in 23 patients and 13-20 months in seven patients). The median interval of recurrence after the primary radiotherapy was only about 11 months (Table 1), much shorter than 24-26 months, the median interval of recurrence of NPC in prior reports. ${ }^{8,24,25} \mathrm{After}{ }^{125} \mathrm{I}$ seed implantation therapy, the total treatment response rate reached $92.1 \%$, and 1-, 2 -, and 3-year survival rates were $80.0 \%, 30.0 \%$, and $6.7 \%$, respectively, with a median survival period of 18 months (Figure 3). In this study, we did not set up a control group because we could not leave recurrent NPC patients with no treatment. Our therapeutic efficacy is similar to a previous study using ${ }^{125}$ I seed implantation therapies, although recurrent NPC patients had a shorter DFI. For example, a recent report has shown that the 1-, 2-, and 3-year survival rates of a total of 19 patients with recurrent NPC after surgery and radiotherapy were $53.0 \%, 18.2 \%$, and $18.2 \%$, respectively, with a median survival period of 13 months. ${ }^{26}$ 
A

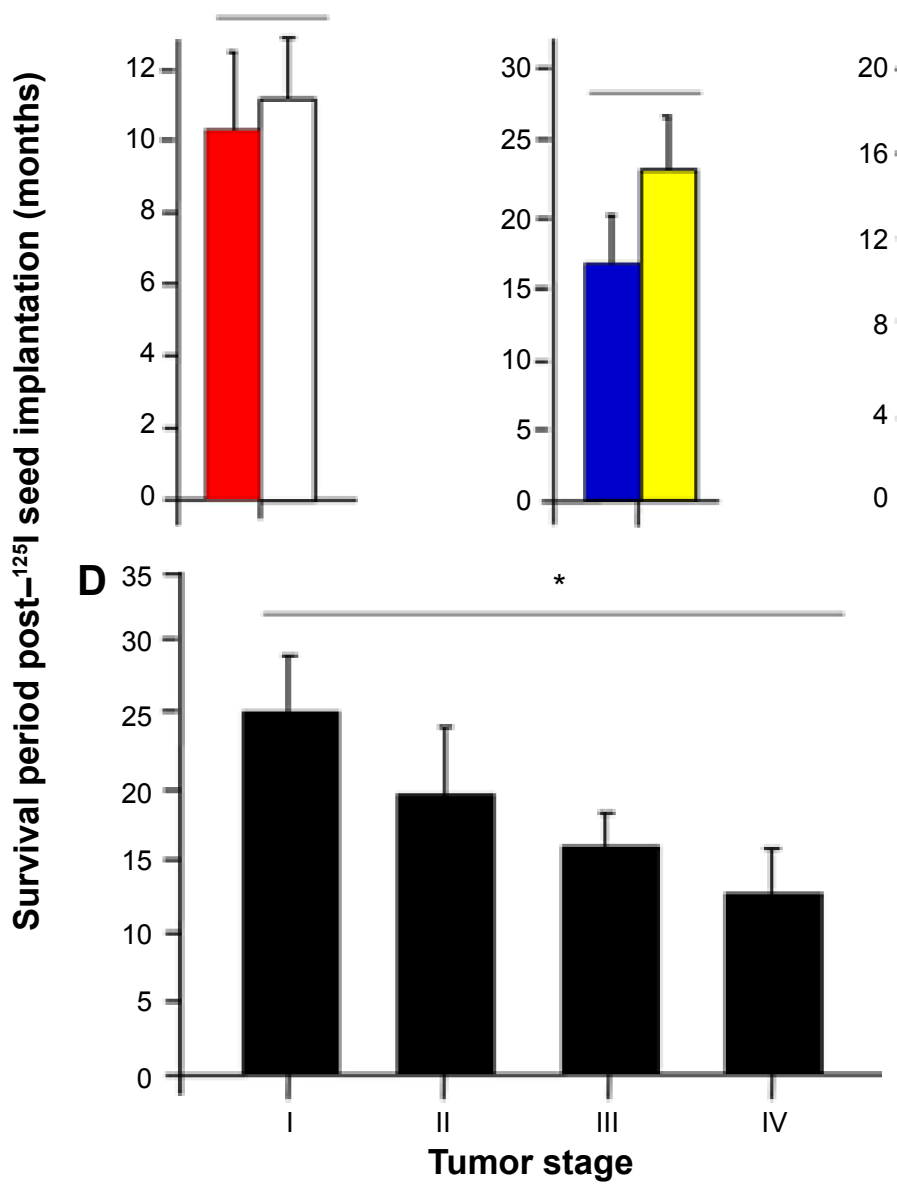

C

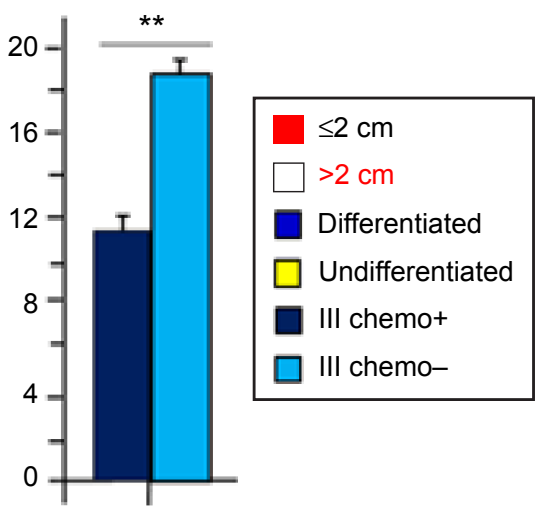

Figure 4 Analyses of survival periods post- ${ }^{125}$ seed implantation therapy and status of NPC.

Notes: $(\mathbf{A})$ The survival period for tumor size $\leq 2 \mathrm{~cm}$ was $10.1 \pm 2.9$ months $(n=7)$ and for tumor size $>2 \mathrm{~cm}$ was $I 1.3 \pm 3.6$ months $(n=23)$, without significant difference $(P>0.05)$. (B) The survival period for differentiated tumor was $16.9 \pm 8.4$ months $(n=23)$ and for undifferentiated tumor was 24 . I \pm 8 .I months ( $n=7)$, without significant difference $(P>0.05)$. (C) The survival period among 13 patients with stage III recurrent NPC was $18.6 \pm 4.7$ months for five patients treated with the primary radiotherapy alone, and was $12.0 \pm 1.9$ months for eight treated with combined radio- and chemotherapy $(* * P<0.0 I)$. (D) The survival period for stage I was $25.4 \pm 8.7$ months ( $n=5)$, for stage II was I $9.8 \pm 9.4$ months $(n=8)$, for stage III was I6.I \pm 4.5 months $(n=8)$, and for stage IV was I2.8 \pm 7.8 months $(n=9)$, with significant differences $(* P<0.05$, ANOVA test).

Abbreviations: ANOVA, analysis of variance; chemo, chemotherapy; NPC, nasopharyngeal carcinoma.

After ${ }^{125}$ I seed implantation, the RR of selected NPC patients was $92.1 \%$ (Table 2). The survival periods post $-{ }^{125} \mathrm{I}$ seed implantation were 4-38 months (Figure 3). Based on the results, we analyzed the possible factors affecting the prognosis. In 30 cases, before recurrence, ten patients had received the primary radiotherapy alone and 20 had received the primary radiotherapy combined with chemotherapy. After ${ }^{125}$ I seed implantation, the survival period of patients with primary radiotherapy alone was $24.3 \pm 7.9$ months, longer than that of patients with the radio- and chemotherapy combination (15.8 \pm 7.9 months). Kaplan-Meier survival analysis demonstrated that $\chi^{2}$ (log rank) was $7.555(P<0.001)$, with very significant difference (Figure 3 ). Among a total 13 patients with stage III recurrent NPC, after ${ }^{125}$ I seed implantation therapy, the survival period of five patients with the primary radiotherapy alone was $18.6 \pm 4.7$ months, longer than that of eight patients with the primary combined radiochemotherapy, 12.0 \pm 1.9 months, with very significant difference $(P<0.01)$ (Figure $4 C)$. These unexpected results were probably caused by a small sample volume but may also be worth investigating for the effects of chemotherapy in the NPC treatment. Our further analyses demonstrated no significant correlation between the survival period and tumor size (Figure 4A) or differentiated and undifferentiated statues (Figure 4B). By performing ANOVA, we found there were significant differences $(P<0.05)$ between survival periods post- ${ }^{125}$ I seed implantation and stages (I, II, III, IV) of recurrent NPC (Figure 4D), suggesting that tumor stage is the most important prognostic factor, which agrees with most results of NPC treatment reports.

Because of the complex anatomy and the rich neurovascular supply in the nasopharynx region, direct implantation 
of radioactive particles is difficult. The ${ }^{125} \mathrm{I}$ seed implantation brachytherapy has been extensively performed in NPC treatment in recent years. CT image guidance improves ${ }^{125} \mathrm{I}$ seed deposition accuracy and delivers a sufficiently high dose to the tumor target, especially for the recurrent carcinoma after radiotherapy. In addition, the ${ }^{125} \mathrm{I}$ radioactivity decreases very rapidly with distance, which reduces the risk of damage to neighboring healthy tissues, organs, or structures in proximity of the targeted tumors. Based on our results and other reports, CT-guided ${ }^{125}$ I seed implantation appears to be a feasible method for the treatment of patients with the recurrent NPC.

\section{Acknowledgment}

The authors gratefully acknowledge the financial support from the Guangdong Province Science and Technology Foundation (grant number 2013B010404028) (to YZ). The funder had no role in study design, data collection and analysis, decision to publish, or preparation of the manuscript.

\section{Disclosure}

The authors report no conflicts of interest in this work.

\section{References}

1. Lozano R, Naghavi M, Foreman K, et al. Global and regional mortality from 235 causes of death for 20 age groups in 1990 and 2010: a systematic analysis for the Global Burden of Disease Study 2010. Lancet. 2012;380(9859):2095-2128.

2. Wang Y, Zhang Y, Ma S. Racial differences in nasopharyngeal carcinoma in the United States. Cancer Epidemiol. 2013;37(6):793-802.

3. Wei WI, Sham JS. Nasopharyngeal carcinoma. Lancet. 2005; 365(9476): 2041-2054.

4. Suárez C, Rodrigo JP, Rinaldo A, Langendijk JA, Shaha AR, Ferlito A. Current treatment options for recurrent nasopharyngeal cancer. Eur Arch Otorhinolaryngol. 2010;267(12):1811-1824.

5. Lee AW, Foo W, Law SC, et al. Total biological effect on late reactive tissues following reirradiation for recurrent nasopharyngeal carcinoma. Int J Radiat Oncol Biol Phys. 2000;46(4):865-872.

6. Su SF, Han F, Zhao C, et al. Treatment outcomes for different subgroups of nasopharyngeal carcinoma patients treated with intensity-modulated radiation therapy. Chin J Cancer. 2011;30(8):565-573.

7. Lee AW, Sze WM, Au JS, et al. Treatment results for nasopharyngeal carcinoma in the modern era: the Hong Kong experience. Int $J$ Radiat Oncol Biol Phys. 2005;61(4):1107-1116.

8. Li JX, Lu TX, Huang Y, Han F, Chen CY, Xiao WW. [Clinical features of 337 patients with recurrent nasopharyngeal carcinoma]. Chin J Cancer. 2010;29(1):82-86. Chinese.

9. Xu T, Tang J, Gu M, Liu L, Wei W, Yang H. Recurrent nasopharyngeal carcinoma: a clinical dilemma and challenge. Curr Oncol. 2013;20(5): e406-e419.

OncoTargets and Therapy

\section{Publish your work in this journal}

OncoTargets and Therapy is an international, peer-reviewed, open access journal focusing on the pathological basis of all cancers, potential targets for therapy and treatment protocols employed to improve the management of cancer patients. The journal also focuses on the impact of management programs and new therapeutic agents and protocols on
10. Yi JL, Gao L, Huang XD, et al. Nasopharyngeal carcinoma treated by radical radiotherapy alone: Ten-year experience of a single institution. Int J Radiat Oncol Biol Phys. 2006;65(1):161-168.

11. Hilaris BS, Lewis JS, Henschke UK. Therapy of recurrent cancer of the nasopharynx. Value of interstitial and intracavitary radiation. Arch Otolaryngol. 1968;87(5):506-510.

12. Wang CC, Busse J, Gitterman M. A simple afterloading applicator for intracavitary irradiation of carcinoma of the nasopharynx. Radiology. 1975;115(3):737-738.

13. Vikram B. "Permanent iodine-125 (I-125) boost after teletherapy in primary cancers of the nasopharynx is safe and highly effective: longterm results". Int J Radiat Oncol Biol Phys. 1997;38(5):1140.

14. Ricke J, Wust P, Stohlmann A, et al. CT-guided interstitial brachytherapy of liver malignancies alone or in combination with thermal ablation: phase I-II results of a novel technique. Int J Radiat Oncol Biol Phys. 2004;58(5):1496-1505.

15. Ricke J, Wust P, Stohlmann A, et al. [CT-guided brachytherapy. A novel percutaneous technique for interstitial ablation of liver metastases] Strahlenther Onkol. 2004;180(5):274-280. German.

16. Jiang YL, Meng N, Wang JJ, et al. Percutaneous computed tomography/ ultrasonography-guided permanent iodine- 125 implantation as salvage therapy for recurrent squamous cell cancers of head and neck. Cancer Biol Ther. 2010;9(12):959-966.

17. Tian Y, Xie Q, Tian Y, et al. Radioactive ${ }^{125} \mathrm{I}$ seed inhibits the cell growth, migration, and invasion of nasopharyngeal carcinoma by triggering DNA damage and inactivating VEGF-A/ERK signaling. PLoS One. 2013;8(9): $\mathrm{e} 74038$.

18. Yan JH, Hu YH, Gu XZ. Radiation therapy of recurrent nasopharyngeal carcinoma. Report on 219 patients. Acta Radiol Oncol. 1983; 22(1):23-28.

19. Lee AW, Law SC, Foo W, et al. Retrospective analysis of patients with nasopharyngeal carcinoma treated during 1976-1985: survival after local recurrence. Int J Radiat Oncol Biol Phys. 1993;26(5):773-782.

20. Gebbia V, Zerillo G, Restivo G, et al. Chemotherapeutic treatment of recurrent and/or metastatic nasopharyngeal carcinoma: a retrospective analysis of 40 cases. Br J Cancer. 1993;68(1):191-194.

21. Suárez C, Llorente JL, Muñoz C, García LA, Rodrigo JP. Facial translocation approach in the management of central skull base and infratemporal tumors. Laryngoscope. 2004;114(6):1047-1051.

22. Teo PM, Kwan WH, Chan AT, Lee WY, King WW, Mok CO. How successful is high-dose $(>$ or $=60 \mathrm{~Gy})$ reirradiation using mainly external beams in salvaging local failures of nasopharyngeal carcinoma? Int $J$ Radiat Oncol Biol Phys. 1998;40(4):897-913.

23. Wang CC. Re-irradiation of recurrent nasopharyngeal carcinoma treatment techniques and results. Int J Radiat Oncol Biol Phys. 1987; 13(7):953-956.

24. Li JX, Lu TX, Huang Y, Han F. Clinical characteristics of recurrent nasopharyngeal carcinoma in high-incidence area. Scientific World Journal. 2012;2012:719754

25. Tian YM, Tian YH, Zeng L, et al. Prognostic model for survival of local recurrent nasopharyngeal carcinoma with intensity-modulated radiotherapy. Br J Cancer. 2014;110(2):297-303.

26. Zhu L, Jiang Y, Wang J, et al. An investigation of $125 \mathrm{I}$ seed permanent implantation for recurrent carcinoma in the head and neck after surgery and external beam radiotherapy. World J Surg Oncol. 2013;11:60.

27. Edge SB, Byrd DR, Compton CC, Fritz AG, Green FL, Trotti III A (editors). AJCC Cancer Staging Manual. 7th ed. New York, NY: Springer; 2010.

\section{Dovepress}

patient perspectives such as quality of life, adherence and satisfaction. The manuscript management system is completely online and includes a very quick and fair peer-review system, which is all easy to use. Visit http://www.dovepress.com/testimonials.php to read real quotes from published authors. 